\title{
REDUKSI AKTIVITAS URANIUM DALAM LIMBAH RADIOAKTIF CAIR MENGGUNAKAN PROSES ELEKTROKOAGULASI
}

\author{
Prayitno, Vemi Ridantami, Imam Prayogo \\ Pusat Sains Teknologi Akselerator - BATAN \\ Jalan Babarsari Kotak Pos 6101 YKBB Yogyakarta 55281, \\ e-mail : prayitno01@batan.go.id
}

(Naskah diterima : 26-07-2016, Naskah direvisi: 19-08-2016, Naskah disetujui: 29-08-2016)

\begin{abstract}
ABSTRAK
REDUKSI AKTIVITAS URANIUM DALAM LIMBAH RADIOAKTIF CAIR MENGGUNAKAN PROSES ELEKTROKOAGULASI. Limbah yang dihasilkan dari proses pengembangan bahan industri bersifat radioaktif yang mengandung uranium yang dapat menimbulkan dampak negatif pada manusia dan lingkungan. Pengolahan limbah radioaktif pada saat ini masih banyak menggunakan bahan-bahan kimia.Penambahanbahan kimiauntuk mereduksi bahan pencemar dinilai kurang efisien karena kurang ramah lingkungan, memerlukan waktu yang lama, dan biaya yang mahal. Untuk itu akan diterapkan metode proses elektrokoagulasi untuk menurunkan aktivitas uranium dari larutan limbah cair. Tujuan penelitian ini adalah untuk mengetahui efisiensi penurunan aktivitas uranium dalam limbah radioaktif cair yang dihasilkan pada proses elektrokoagulasi dengan variasi tegangan, waktu tinggal, jarak elektroda dan $\mathrm{pH}$ inlet limbah. Limbah simulasi yang digunakan memiliki kadar kontaminan uranium sebesar $500 \mathrm{mg} / \mathrm{L}$. Percobaan ini dilakukan dengan metode batch dengan elektroda aluminium. Hasil penelitian diperoleh parameter optimal pada tegangan $12,50 \mathrm{~V}$, jarak $1 \mathrm{~cm}, \mathrm{pH} 7$, dan waktu proses selama 60 menit diperoleh efisiensi penurunan limbah uranium sebesar $97,20 \%$.
\end{abstract}

Kata Kunci:elektrokoagulasi, reduksi limbah uranium, tegangan, aluminium. 


\section{ABSTRACT}

REDUCTION OF URANIUM ACTIVITIES IN LIQUID WASTE RADIOACTIVE BY USING OF ELCTROCOAGULATION PROCESS. Waste generated from the process of the industrial material development one of which waste containing uranium radioactive, can have negative impact on humans and the environment. In the present time, chemicals are still mostly use in radioactive waste treatment. To reduce pollutants with the use of chemicals is less efficient, because less environmentally friendly, take long time and costly. Therefore, a system of electrocoagulation process will be applied to decrease the activity of uranium from waste solution. The purpose of this study is to determine the efficiency of uranium activity decrease in waste water which is produced in the electrolysis process is conducted with voltage variations, the dwelling time, electrode spacing, and the waste inlet $\mathrm{pH}$. The waste that will be treated has uranium contaminant levels of $500 \mathrm{mg} / \mathrm{L}$. The experiment was conducted by a batch system with aluminum electrodes. Parameters affecting electrocoagulation process, such as voltage, time, distance electrode, and the $\mathrm{pH}$ have been studied and the best voltage optimization condition has been obtained of $12.50 \mathrm{~V}$, a distance of $1 \mathrm{~cm}, \mathrm{pH} \mathrm{7}$, and in the processing time of 60 minutes efficiency of $97.20 \%$ was obtained.

Keywords: electrocoagulation, reduction of uranium waste, voltage, aluminium. 


\section{PENDAHULUAN}

Limbah yang dihasilkan dari proses pengembangan bahan industri yang mengandung uranium, dapat menimbulkan dampak negatif pada manusia dan lingkungan. Uranium merupakan unsur yang banyak terdapat di alam dengan waktu paruh panjang sekitar 4,46 miliar tahun. Selain itu, uranium merupakan salah satu logam berat dengan toksisitas tinggi dikarenakan sifatnya yang beracun dan radioaktif.

Uranium merupakan unsur alam tidak stabil yang dapat meluruh menjadi unsur lain atau yang disebut zat radioaktif. Dalam proses peluruhan uranium akan dilepaskan jenis radiasi yang dapat menyebabkan kanker, kerusakan genetik, gangguan hormon dan mengurangi jumLah sel darah. Kadar uranium sebesar $1000 \mu \mathrm{g} / \mathrm{L}$ dalam air minum telah terbukti menyebabkan kerusakan ginjal pada manusia ${ }^{[1]}$. Oleh karena itu, limbah radioaktif cair yang mengandung uranium harus dikelola dengan baik apabila masuk ke dalam perairan seperti sungai, danau, muara maupun laut yang dapat mengkontaminasi air minum bila diambil dari sungai ataupun secara tidak langsung dapat mengkontaminasi produk pertanian dan perikanan.

Pengelolaan limbah cair di Pusat Sains Teknologi Aselarator (PSTA) - BATAN dilakukan dengan cara menampung limbah cair tersebut kemudian dilakukan pengolahan limbah secara kimia dan fisika yaitu dengan pemakaian bahan koagulan, evaporasi dan penukar ion. Pengolahan secara kimia harus dipertimbangkan dalam hal penggunaan bahan kimia yang dapat menimbulkan pencemaran lingkungan. Selain itu, proses pengolahan kimia pada efluent masih sedikit mengandung logam berat dan zat padat terlarut sehingga belum dapat dibuang ke lingkungan ${ }^{(2)}$. Pengolahan limbah cair secara fisika seperti evaporasi, penukar ion, reverse osmosis, memerlukan biaya yang cukup mahal dan tidak cukup efektif untuk memindahkan kontaminan dalam air $^{[3]}$.

Beberapa tahun belakangan ini telah dikembangkan suatu alternatif pengolahan limbah cair menggunakan elektrokoagulator. Elektrokoagulasi diakui sebagai metode pengolahan berbagai jenis limbah dengan proses yang efektif ${ }^{[4]}$. Proses pengolahan limbah dengan metode ini dapat mengurangi biaya operasi, perawatan dan tidak menggunakan bahan kimia, sehingga perlu dilakukan studi terkait metode tersebut jika digunakan untuk pengolahan limbah yang mengandung uranium.

Koagulasi adalah suatu fenomena dimana partikel bermuatan dalam suspense koloid dinetralkan oleh tumbukan dengan ion yang berlawanan muatan, kemudian mengumpul dan dikuti oleh proses sedimentasi. Pada proses elektrokoagulasi terdapat dua gaya yang berperanyaitu:

1. Gaya tolak elektrostatik yang membuat system stabil

2. Gaya tarik Van der Waals.

Proses elektrokoagulasi terjadi karena pengendapan elektrokoagulasi dengan adanya medan listrik diantara dua elektrode sehingga ion $\mathrm{Al}$ terlepas dari anoda melalui reaksi oksidasi. Ion tersebut terhidrolisa menjadi hidroksida kompleks yang disebut sebagai koagulan yang akan mengikat kontaminan dalam limbah yang kemudian terjadi adsorbsi oleh partikelpartikel bermuatan negatif membentuk koloid bermuatan negatif akan mengikat kontaminan dalam limbah yang ada di sekitarnya ${ }^{[5]}$

Proses elektrokoagulasi merupakan proses elektrokoagulasi yang secara simultan memisahkan logam berat, padatan yang larut, zat organik yang teremulsi dan kontaminan lainnya dari limbah cair. Dalam proses elektrokoagulasi, arus listrik dialirkan melalui elektroda logam. Elektroda logam 
dalam proses elektro koagulasi terdiri dari dua jenis yaitu katoda dan anoda. Katoda berfungsi sebagai kutub negative terbuat dari platina atau karbon. Katoda disebut juga sebagai elektroda inert, yaitu elektroda yang tidak mengalami perubahan saat elektrokoagulasi. Anoda berfungsi sebagai kutub positif bahan yang paling umum digunakan adalah besi atau aluminium, anoda disebut juga sebagai anoda, karena kation yang dihasilkan dari anoda akan larut dalam air. Proses anoda aluminium menghasilkan kation monomerik seperti $\mathrm{Al}^{3+}$ dan $\mathrm{Al}(\mathrm{OH})_{2}{ }^{+}$pada $\mathrm{pH}$ rendah, yang mana pada nilai $\mathrm{pH}$ ini dapat diubah menjadi $\mathrm{Al}(\mathrm{OH})_{3}$ dan akhirnya berpolimerisasi menjadi $\mathrm{Al}_{n}(\mathrm{OH})_{3 n}$ berdasarkan persamaan reaksi berikut:

$$
\begin{array}{ll}
\mathrm{Al} & \rightarrow \mathrm{Al}^{3+}{ }_{(\mathrm{aq})}+3 \mathrm{e}^{-} \\
\mathrm{Al}^{3+}{ }_{(\mathrm{aq})}{ }^{+} \mathrm{H}_{2} \mathrm{O} & \rightarrow \mathrm{Al}(\mathrm{OH})_{3}+3 \mathrm{H}^{+}{ }_{(\mathrm{aq})} \\
n \mathrm{nl}(\mathrm{OH})_{3} & \rightarrow \mathrm{Al}_{n}(\mathrm{OH})_{3 \mathrm{n}}
\end{array}
$$

Pengaruh $\mathrm{pH}$ pada medium larutan atau ion lain seperti $\mathrm{Al}(\mathrm{OH})^{2+}, \mathrm{Al}_{2}(\mathrm{OH})_{2}{ }^{4+}$ dan $\mathrm{Al}(\mathrm{OH})_{4}$ dapat dibuat dalam suatu metode elektro koagulasi.

Beberapa faktor yang mempengaruhi proses elektrokoagulasi antara lain:

1. Kerapatan arus listrik

Kenaikan kerapatan arus akan mempercepat ion bermuatan membentuk endapan berupa flok-flok. Jumlah arus listrik yang mengalir berbanding lurus dengan bahan yang dihasilkan selama proses

\section{Waktu}

Menurut hukum Faraday, jumlah muatan yang mengalir selama proses elektrolisis sebanding dengan jumlah waktu kontak yang digunakan.

\section{Tegangan}

Aruslistrik yang menyebabkan perubahan kimia mengalir melalui medium (logam atau elektrolit) akibat adanya beda potensial, tahanan listrik pada medium lebihbesar dari logam, maka yang perlu diperhatikan adalah mediumnya dan batas antar logam dan medium.

4. Kadar keasaman $(\mathrm{pH})$

Pada proses elektrokoagulasi terjadi proses elektrolisis air yang menghasilkan gas hydrogen dan ion hidroksida. Semakin lama waktu kontak, maka pembentukan gas hldrogen dan ion hidroksida makin cepat juga. Apabila ion hidrokdsida yang dihasilkan lebih banyak maka akan menaikkan $\mathrm{pH}$ larutan dengan mudah dapat diubah menjadi $\mathrm{pH}$ optimal dalam larutan dari nilai 6,5 sampai 7,5 .

\section{Ketebalan plat}

Semakin tebal plat elektroda yang digunakan, daya tarik elektrostatik dalam mereduksi dan mengoksidasi ion logam dalam larutan semakin besar

6. Jarak antar elektroda

Jarak antara elektroda mempengaruhi besarnya hambatan elektrolit, semakin jauh jaraknya semakin besar hambatannya sehingga semakin kecil arus yang mengalir.

Selama proses elektrokoagulasi terjadi reaksi reduksi oksidasi, hasil hidrolisis yang mengandung logam uranium akan direduksi dan diendapkan di kutub negatif (katoda), sedangkan elektroda positif (anoda) akan teroksidasi menjadi $\mathrm{Al}(\mathrm{OH})_{3}$ yang berfungsi sebagai koagulan.

Bila menggunakan elektroda alumunium reaksi yang terjadi adalah sebagai berikut $^{[68]}$.

Reaksi pada anoda

$\mathrm{Al}_{(\mathrm{s})} \quad \rightarrow \mathrm{Al}^{3+}{ }_{(\mathrm{aq})}+3 \mathrm{e}^{-}$

$\mathrm{Al}^{3+}{ }_{(\mathrm{aq})}+3 \mathrm{OH}_{(\mathrm{aq})}^{-} \quad \rightarrow \mathrm{Al}(\mathrm{OH})_{3(\mathrm{~s})}$

Reaksi pada katoda

$3 \mathrm{H}_{2} \mathrm{O}_{(l)}+3 \mathrm{e}^{-} \rightarrow 1,5 \mathrm{H}_{2(\mathrm{~g})}+3 \mathrm{OH}_{(\mathrm{aq})}^{-}$

Reaksi Keseluruhan:

$\mathrm{Al}_{(\mathrm{s})}+3 \mathrm{H}_{2} \mathrm{O}_{(\mathrm{l})} \quad \rightarrow \mathrm{Al}(\mathrm{OH})_{3(\mathrm{~s})}+1,5 \mathrm{H}_{2(\mathrm{~g})}$ 
Apabila dalam suatu elektrolit ditempatkan dua elektroda dan dialiri arus listrik searah, maka akan terjadi peristiwa elektrokimia yaitu gejala dekomposisi elektrolit, dimana ion positif (kation) bergerak ke katoda dan menerima elektron yang direduksi dan ion negatif (anion) bergerak ke anoda dan menyerahkan elektron yang dioksidasi. Mekanisme reaksi yang terjadi pada proses ini seperti yang ditunjukkan pada Gambar 1. ${ }^{[8]}$

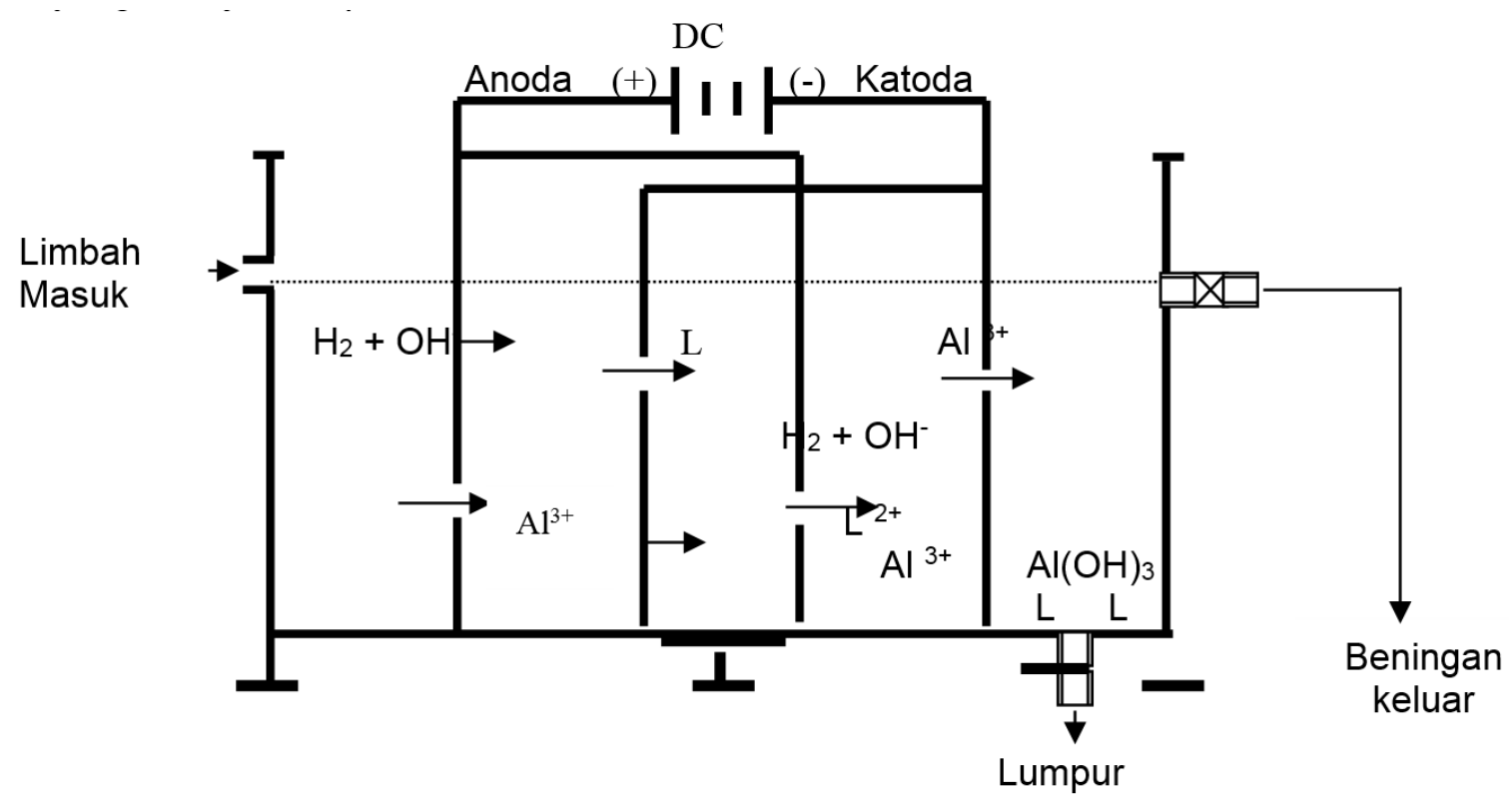

Gambar1.Mekanisme proses elektrokoagulasi ${ }^{[8,9]}$

1. Reaksipada katoda:

Ion $\mathrm{H}^{+}$dari suatu asam akan direduksi menjadi gas hidrogen yang akan bebas sebagai gelembung-gelembung gas:

$2 \mathrm{H}^{+}+2 \mathrm{e} \quad \rightarrow \mathrm{H}_{2}$

Larutan yang mengalami reduksi adalah pelarut (air) dan terbentuk gas hydrogen $\left(\mathrm{H}_{2}\right)$ pada katoda:

$$
2 \mathrm{H}_{2} \mathrm{O}+2 \mathrm{e} \rightarrow 2 \mathrm{OH}^{-}+\mathrm{H}_{2}
$$

2. Reaksi pada anoda

Anoda terbuat dari logam aluminium akan teroksidasi.

$\mathrm{Al}^{\circ}+3 \mathrm{H}_{2} \mathrm{O} \rightarrow \mathrm{Al}(\mathrm{OH})_{3}+3 \mathrm{H}^{+}+3 e$

Ion $\mathrm{OH}^{-}$dari basa akan mengalami oksidasi membentuk gas oksigen $\left(\mathrm{O}_{2}\right)$,

$4 \mathrm{OH}^{-} \rightarrow 2 \mathrm{H}_{2} \mathrm{O}+\mathrm{O}_{2}+4 \mathrm{e}$

Jikalarutan mengandung ion-ion logam lain maka ion-ion logam akan direduksi menjadi logamnya dan terdapat pada batang katoda:

$$
\mathrm{L}^{+}+\mathrm{e} \quad \rightarrow \mathrm{L}^{\circ}
$$

Dari reaksi tersebut, pada anoda akan dihasilkan gas, buih dan flok $\mathrm{Al}(\mathrm{OH})_{3}$. Flok yang terbentuk selanjutnya akan mengikat logam uranium yang ada di dalam limbah, sehingga flok akan memiliki kecenderungan mengendap. Dari persamaan reaksi kimia di atas terlihat pembentukan gas oksigen dan hidrogen mempengaruhi reduksi aktivitas uranium. Gas hidrogen membantu kotaminan yang mengapung atau terangkat. Hal ini menyebabkan tereduksinya bahan terlarut termasuk flok $\mathrm{Al}(\mathrm{OH})_{3}$ yang mengikat uranium yang ada didalam limbah cair sertamenangkap sebagian limbah organik yang tidak terdapat pada batang katoda.

Gas $\mathrm{H}_{2}$ yang ditimbulkan dari reaksi redoks menyebabkan bahan organik dapat 
tereduksi. Sebagian molekul yang terdapat pada limbah ditangkap oleh ion $\mathrm{Al}(\mathrm{OH})_{3}$ kemudian penyisihan oleh $\mathrm{H}_{2}$ sebagai senyawa organik membentuk gelembung yang dapat menurunkan uranium dalam air limbah. Ketika medan magnet diantara plat elektroda masih cukup besar, sistem ionik dari polutan limbah cenderung akan berkompeten membentuk suatu flok-flok dengan ukuran yang jauh lebih besar sehingga proses oksidasi pada plat anoda juga semakin besar. Oleh karena itu larutan nampak lebih keruh karena diakibatkan terjadinya pembentukan flok oleh $\mathrm{Al}(\mathrm{OH})_{3}$ pada bak elektrokoagulasi. Tetapi penurunan yang terjadi sudah memenuhi baku mutu limbah cair.

\section{a. Proses elektrokoagulasi}

Penurunan radioaktivitas uranium dalam limbah cair pada penelitian ini dilakukan dengan proses elektrokoagulasi menggunakan elektroda alumunium yang disusun secara paralel dalam reactor batch dan dihubungkan dengan arus DC seperti rangkaian yang ditunjukkan pada Gambar 2 .

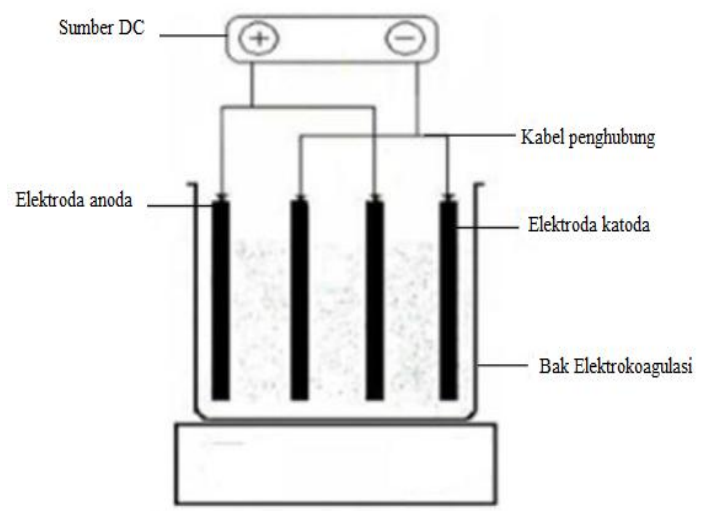

Gambar 2.Susunan elektroda paralel ${ }^{[10]}$

Elektroda disusun paralel berarti arus dibagi diantara semua elektroda, sehingga tegangan yang dibutuhkan lebih rendah dibandingkan rangkaian seri ${ }^{[10]}$. Prinsip dasar proses ini adalah reaksi oksidasi dan reduksi (redoks). Pada elektroda anoda terjadi peristiwa oksidasi, sedangkan pada katoda terjadi reaksi reduksi. Limbah cair yang mengandung uranium berfungsi sebagai larutan elektrolit. Energi listrik akan mengalir melalui katoda menuju anoda sehingga pada katoda menjadi bermuatan negatif dan ion-ion logam yang berada pada larutan elektrolit akan ditarik pada katoda ${ }^{[11]}$.Proses reaksi oksidasi pada anoda akan mengakibatkan larutnya logam alumunium menjadi ion $\mathrm{Al}^{3+}$, yang akan mengalami reaksi hidrolisis menghasilkan $\mathrm{Al}(\mathrm{OH})_{3}$ berbentuk padatan yang tidak dapat larut dalam air yang berfungsi sebagai koagulan. selanjutnya koagulan akan mengikat kontaminankontaminan dalam limbah cair yang diolah. Interaksi logam dengan $\mathrm{OH}^{-}$dalam bentuk hidrosida yang mana mempunyai kemampuan adsorbsi yang tinggi dalam mengikat polutan dalam limbah (bridge coagulation), seperti pada persamaan reaksi ${ }^{(6,8)}$ (4), (5), (6) dan (7). Adanya gas $\mathrm{H}_{2}$ yang dihasilkan membuat ion hidroksida yang mengikat polutan dalam limbah menjadi senyawa yang tidak larut yang akan mengalami pengapungan ke permukaaan reaktor atau disebut flotasi. ${ }^{[10,12]}$.

\section{METODOLOGI}

\section{a. Pembuatan limbah simulasi}

Limbah simulasi yang digunakan adalah larutan uranil nitrat heksahidrat (UNH). Serbuk UNH ditimbang 1,0546 gr, kemudian dilarutkan dengan aquadest dalam labu takar $1000 \mathrm{~mL}$. Limbah larutan diukur pHdanaktivitas alpha sebelum digunakan sebagai inlet proses elektrokoagulasi.

\section{b. Proses elektrokoagulasi}

Limbah cair simulasi yang telah dibuat dimasukkan ke dalam bak elektrokoagulasi. Setelah bak elektro koagulasi penuh dengan limbah, arus listrik searah dialirkan dengan menghidupkan adaptor denganvariasi tegangan $5 \mathrm{~V}, 10 \mathrm{~V}$, dan $15 \mathrm{~V}$ serta waktu operasi proses elektrokoagulasi divariasi $0,10,20,30,40,50$, dan 60 menit. Nilai optimum tegangan dan waktu tinggal 
digunakan untuk menentukan nilai optimum jarak elektroda $1 \mathrm{~cm}, 2 \mathrm{~cm}, 3 \mathrm{~cm}$. Nilai optimum tegangan, waktu, dan jarak antar elektroda serta $\mathrm{pH}$. Hasil proses elektrokoagulasi diambil sampel untuk masing-masing parameter dan dilakukan karakterisasi kadar radioaktif alpha-beta.

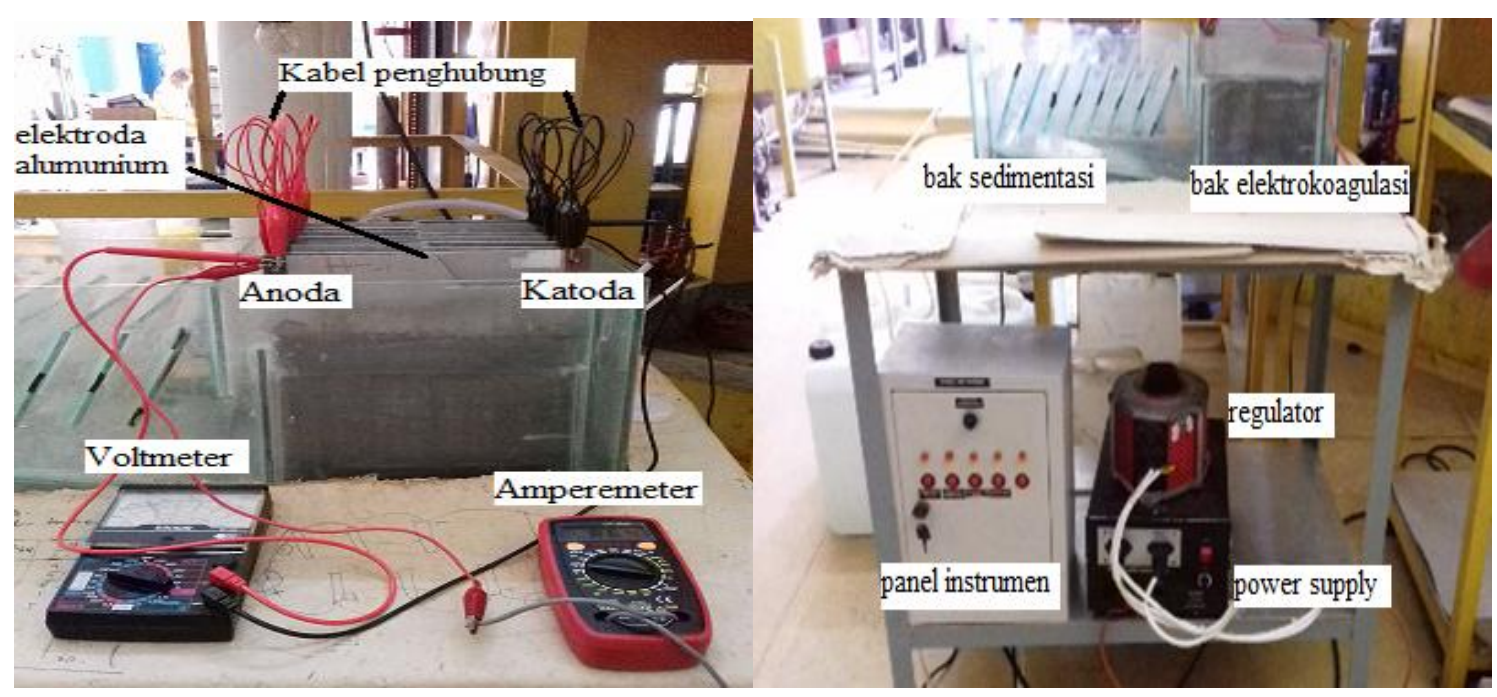

Gambar 3. Alat elektrokoagulator

\section{c. Preparasi analisis limbah}

Sampel limbah cair dari bak elektrokoagulasisebanyak $10 \mathrm{~mL}$, kemudian disiapkan planset yang sudah diketahui beratnya dan sudah dibersihkan dengan asam nitrat $0,1 \mathrm{~N}$. Limbah cair yang mengandung uranium sedikit demi sedikit dituangkan kedalam planset sambil sampel dikeringkan di atas lampu pemanas. Setelah sampel kering dimasukkan ke dalam desikator dan selanjutnya residu dalam planset ditimbang.

\section{d. Analisisradio aktivitas limbah}

Pengambilan sampel limbah cair dari bak elektrokoagulasi, dilakukan pencacahan, dicatat hasil pencacahan background.

\section{HASIL DAN PEMBAHASAN}

Proses pengapungan atau flotasi terjadi karena gas $\mathrm{H}_{2}$ yang dihasilkan pada elektroda katoda yang melewati media air limbah sehingga terjadi gaya dorong ke arah permukaan. Ketika gelembung bergerak ke atas, gelembung akan mengikat partikel padat yang terdispersi dalam air limbah secara fisik untuk didorong ke permukaan yang dipengaruhi oleh gaya gravitasi dan disperse ${ }^{[12]}$. Anoda berfungsi sebagai koagulan dalam proses koagulasi-flokulasi proses tersebut dan katoda akan menghasilkan gelembung-gelembung gas hidrogen yang berfungsi menaikkan flok-flok yang tersuspensi. Mekanisme pada proses elektrokoagulasi ada beberapa diantaranya perpindahan dan penetralan kation atau ion hydroxyl $\left(\mathrm{OH}^{-}\right)$yang dihasilkan akan mengendap dengan polutan seperti yang nampak pada Gambar 4. 


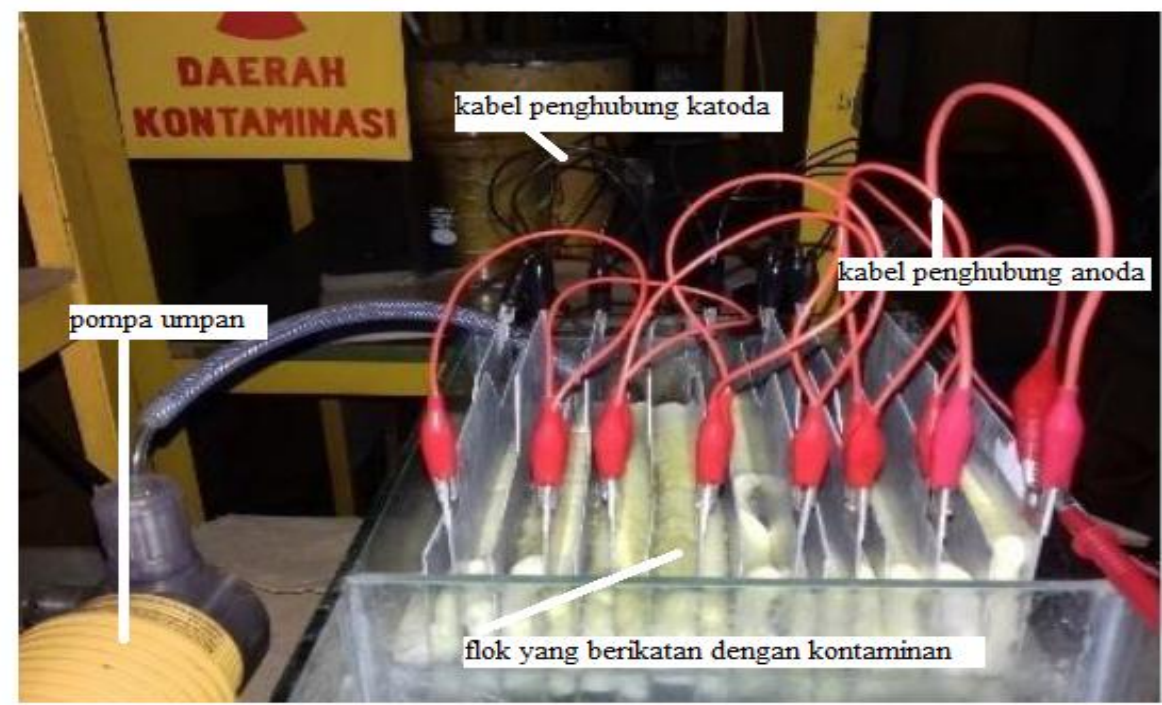

Gambar 4. Proses elektrokoagulasi yang menghasilkan endapan dalam permukaan reaktor

Elektroda aluminium yang digunakan pada proses elektrokoagulasi secara berulang, lama-kelamaan akan mengalami perubahan elektroda seperti yang terlihat pada Gambar 5.

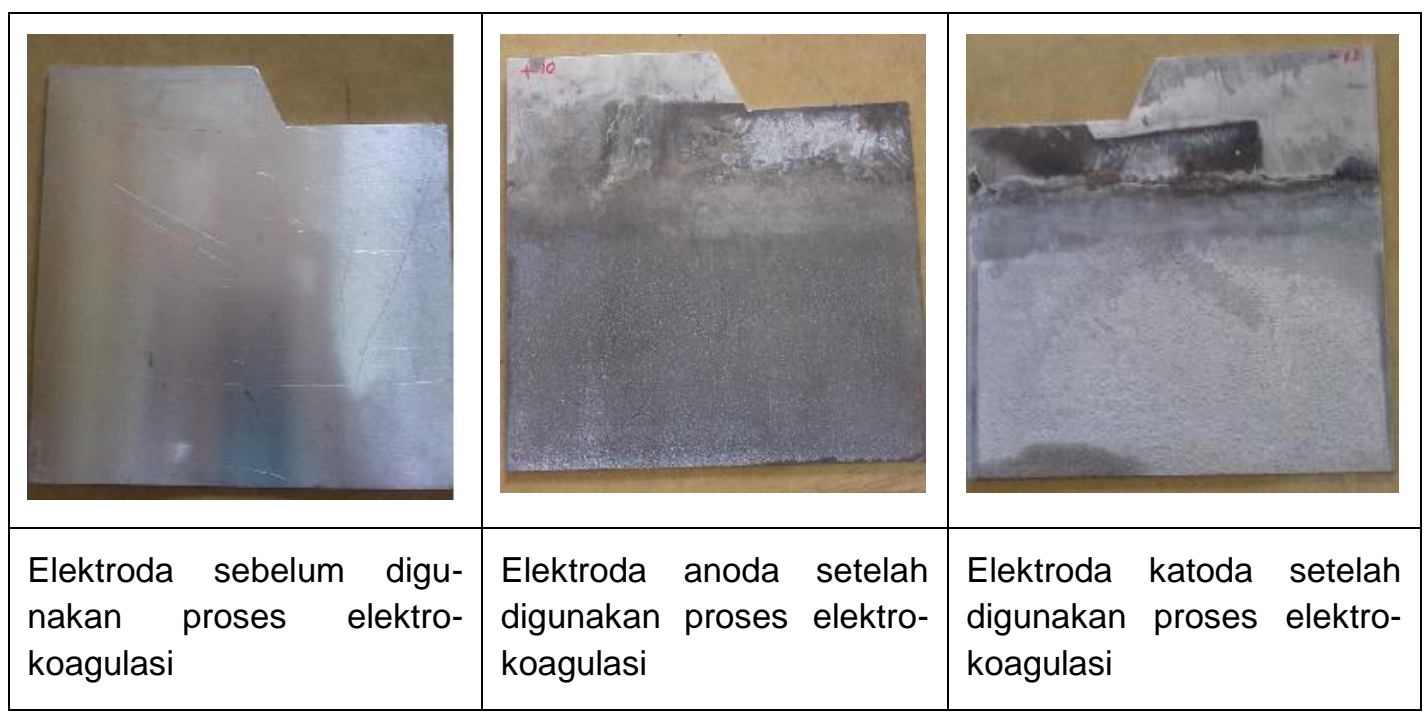

Gambar 5. Perbedaan fisik elektroda sebelum dan setelah digunakan

$\begin{array}{ll}\text { Gambar } 5 & \text { menunjukkan terjadi } \\ \text { perubahan fisik elektroda sebelum }\end{array}$ dansetelah digunakan baik pada anoda maupun katoda. Elektroda yang baru nampak mengkilat dengan warna keperakan. Elektroda anoda setelah proses, nampak terjadi perubahan warna dari warna keperakan mengkilat berubah menjadi abu kehitaman, sedikit kusam, dan mengalami penipisan yang ditunjukkan dari pengu- rangan berat plat elektroda pada Tabel 1 . Elektroda katoda menjadi lebih tebal karena ada penambahan berat. Hal ini terjadi karena pada anoda terjadi reaksi oksidasi yang melepaskan ion $\mathrm{Al}$ dan ditarik ke katoda, sehingga seiring waktu berjalan elektroda mengalami perubahan berat. Pembentukan lapisan pada elektroda dapat menghambat transfer elektron pada proses elektrokoagulasi. ${ }^{[13]}$ 
Tabel 1. Berat elektroda sebelum dan sesudah proses elektrokoagulasi

\begin{tabular}{|c|c|c|c|c|c|c|}
\hline \multirow{2}{*}{$\begin{array}{c}\text { No } \\
\text { Plat }\end{array}$} & \multicolumn{2}{|c|}{ Berat plat anoda $(\mathrm{g})$} & \multicolumn{2}{c|}{ Berat plat katoda $(\mathrm{g})$} & \multicolumn{2}{c|}{ Selisih berat $(\mathrm{g})$} \\
\cline { 2 - 7 } & Sebelum & Sesudah & Sebelum & Sesudah & Anoda & Katoda \\
\hline 1 & 135,193 & 135,136 & 132,110 & 137,797 & $-0,057$ & 5,687 \\
2 & 132,117 & 131,779 & 133,547 & 139,144 & $-0,338$ & 5,597 \\
3 & 132,364 & 132.026 & 137,868 & 144,158 & $-0,338$ & 6,290 \\
4 & 135,308 & 135,070 & 138,126 & 144,024 & $-0,238$ & 5,898 \\
5 & 133,433 & 133,156 & 138,133 & 143,259 & $-0,277$ & 5,126 \\
6 & 135,560 & 135,496 & 137,606 & 141,408 & $-0,064$ & 3,802 \\
7 & 133,800 & 133,720 & 135,744 & 140,521 & $-0,080$ & 4,777 \\
8 & 132.720 & 132,496 & 135,489 & 138,079 & $-0,224$ & 2,590 \\
\hline
\end{tabular}

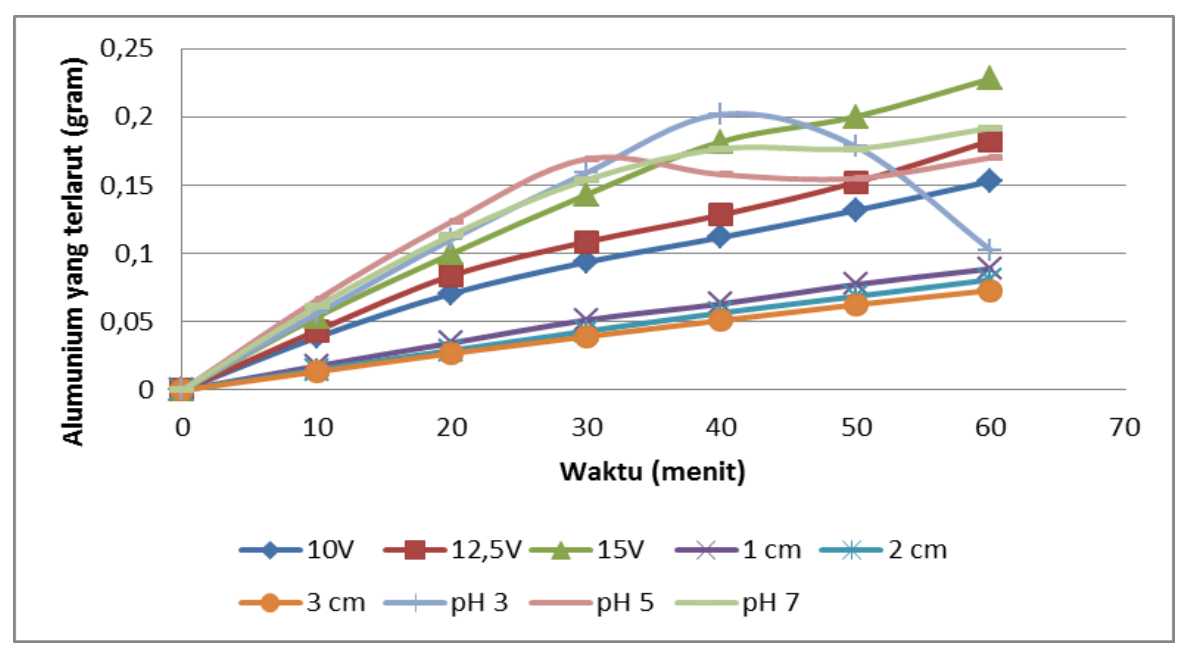

Gambar 6. Pengaruh waktu proses terhadap tegangan, jarakelektroda dan $\mathrm{pH}$

Gambar 6 menunjukkan bahwa variasi tegangan, jarak elektroda dan $\mathrm{pH}$ berpengaruh terhadap jumlah alumunium yang terlarut dalam proses elektrokoagulasi. Semakin tinggi tegangan alumunium yang terlarut semakin meningkat. Hal ini terjadi ada hubungannya dengan hukum Faraday. Alumunium yang terlarut berbanding lurus dengan arus pada proses elektrokoagulasi. Meningkatnya tegangan membuat arus meningkat yang mengakibatkan alumunium yang terlarut meningkat. Jarak elektroda semakin pendek, alumunium yang terlarut semakin besar. Jarak elektroda pendek membuat hambatan dalam proses semakin kecil, sehingga arus dalam proses elektrokoagulasi meningkat, akibatnya alumunium yang terlarut dalam proses juga meningkat. $\mathrm{pH}$ larutan mempengaruhi proses elektro- koagulasi dalamproduksi $\mathrm{Al}(\mathrm{OH})_{3}$. Gambar 6 menunjukkan bahwa pada saat $\mathrm{pH} 3$ danpada menit ke 50 dan 60 aluminium yang terlarut mengalami penurunan. Kecenderungan penurunan juga nampak pada $\mathrm{pH} 5$ dan 7 padamenit ke 50 . Hal ini terjadi karena pada menit ke 50 elektroda alumunium mengalami kejenuhan akibat pembentukan flok yang menutupi permukaan elektroda, sehingga kemampuan elektroda dalam pembentukan ion $\mathrm{Al}^{3+}$ menurun. Pada $\mathrm{pH} 5$ dan $\mathrm{pH} 7$ pada menit ke 60 alumunium terlarut mengalami kenaikan. Hal ini terjadi karena proses elektrokoagulasi berjalan simultan. Pembentukan flok meningkat seiring berjalannya waktu. Terbentuknya gas $\mathrm{H}_{2}$ dalam proses membuat flok-flok yang terbentuk saling bertumbukan. Tumbukan antar flok mem- 
buat kenaikan berat jenis yang membuat flok turun ke dasar reaktor. Akibatnya, reaksi redoks tidak terhalang oleh keberadaan flok yang menempel di elektroda sehingga aluminum yang terlarut dapat meningkat kembali.

Berkurangnya aktivitas uranium pada limbah cair diduga karena adanya beberapa macam reaksi. Reaksi yang terjadi dalam larutan pada proses elektrokoagulasi adalah migrasi ke elektroda yang bermuatan berlawanan (electrophoresis) danpenggabungan (aggregation) untuk membentuk senyawa netral. Kation atau ion hidroksi $\left(\mathrm{OH}^{-}\right)$membentuk endapan dengan polutan $^{[7]}$. Logam kation berinteraksi dengan ion $\mathrm{OH}^{-}$membentuk hidroksi yang mengadsorbsi polutan (bridge coagulation), hidroksi membentuk flok-flok dan member-sihkan polutan (sweep coagulation) oksidasi polutan. Hal ini mengurangi toksitasnya, penyisihan melalui elektrolisis dan adhesi gelembung udara ${ }^{[8])}$.

Hal ini membuktikan kesesuaian terhadap teori double layer bahwa lingkaran terdalam akan disi oleh koagulan bermuatan positip dan akan menyerap ion-ion negatip yang terletak pada lingkaran lebih luas. Muatan positip dan negatip bertemu maka terjadi gaya Van der Waals (tarik menarik) antar kedua ion tersebut sehingga terjadi ikatan yang sangat kuat dan terbentuklah koagulan yang selanjutnya membentuk flok yang dapat menarik logam dan pengotor dalam limbah cair ${ }^{[14]}$.

Hal ini sangat berhubungan dengan tegangan, semakin besar tegangan yang diberikan, maka semakin banyak flok-flok yang dapat mengikat pencemar limbah. Flok yang dihasilkan sebagian dapat mengendap dan sebagian lagi ada yang terflotasi kepermukaan. Jika selama proses elektrokoagulasi tegangan yang diberikan semakin besar, maka semakin lama waktu yang dibutuhkan karena flok yang terbentuk semakin banyak.

Tegangan listrik yang diterima elektroda mempengaruhi kemampuan elektroda untuk membentuk koagulan, karena semakin besar tegangan yang diterima maka jumlah ion $\mathrm{Al}^{3+}$ yang dilepaskan oleh anion pada elektroda akan semakin besar. Penurunan berat elektroda atau yang terlarut dipengaruhi oleh tegangan, $\mathrm{pH}$ dan lama waktu proses elektrokoagulasi. Bahan aluminium terlarut pada tegangan 15 volt, waktu proses 60 menit, $\mathrm{pH} 7$ dan jarak elektroda $1 \mathrm{~cm}$ adalah $0,2 \mathrm{~g}$.

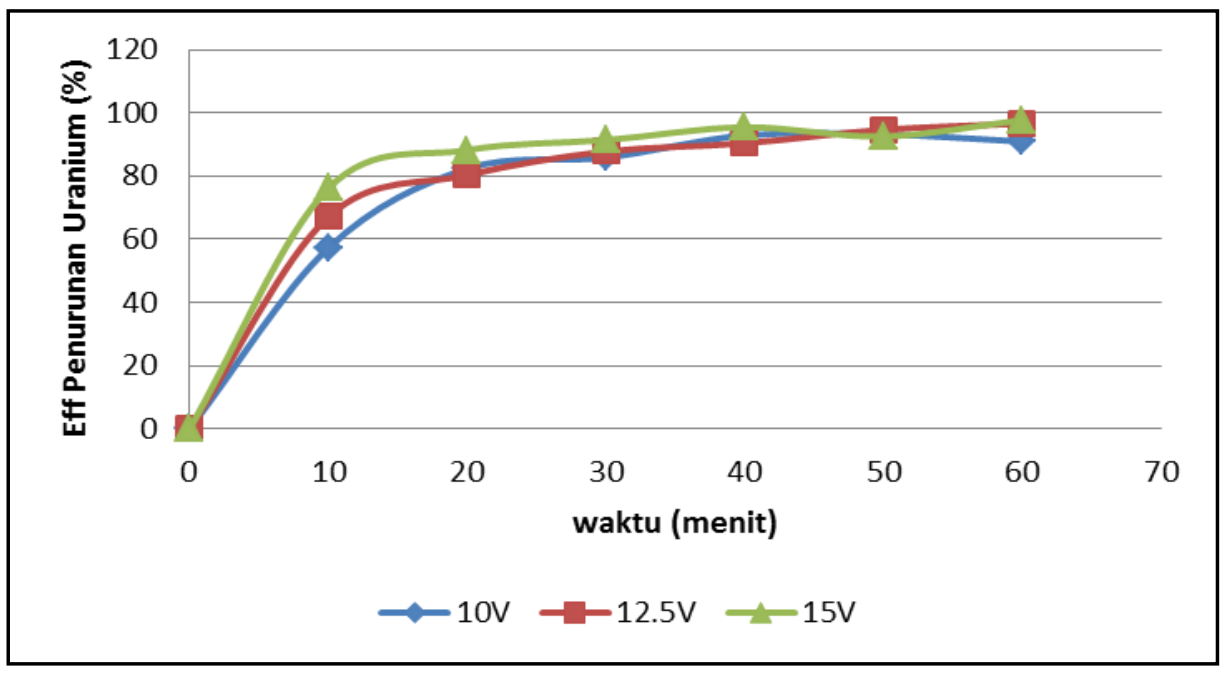

Gambar 7. Hubungan waktu proses dan tegangan terhadap effsiensipenurunan uranium dalam limbah 
Gambar 7 menunjukkan bahwa setiap perubahan tegangan akan menghasilkan effisiensi elektrokoagulasi yang berbeda. Semakin besar tegangan, semakin rendah aktivitas uranium dalam filtrat yang diperoleh. Hal ini terjadi untuk setiap perubahan waktu elektrokoagulasi dansemakin lama waktu kontak maka kadar uranium dalam filtrat semakin rendah. Reduksi kadar uranium dalam limbah terbesar dicapai pada tegangan 15 Volt dan waktu kontak 60 menit.Pada kondisi ini kadar uranium dalam filtrat sebesar 0,30 ppm.

Meningkatnya arus-listrik membuat oksidasi elektroda aluminium meningkat sesuai dengan Hukum Faraday I dimanamassa zat yang dihasilkan pada elektroda selama proses elektrokoagulasi akan berbanding lurus dengan banyaknya elektron yang diberikan pada elektroda seperti ditunjukkan pada Gambar 7. Semakin tinggi arus maka tegangan yang dihasilkan semakin besar dan aluminium yang terlarut semakin banyak sehingga kenaikan tegangan secara tidak langsung berpe-ngaruh dalam produksi $\mathrm{Al}(\mathrm{OH})_{3}$ yang terbentuk. Arus semakin besar maka produksi $\mathrm{Al}(\mathrm{OH})_{3}$ meningkat, sehingga effisiensi penurunan aktivitas semakin baik $^{[15]}$.
Pengaruh kuat arus terhadap nilai efisiensi penurunan aktivitas uranium dinyatakan sebagai efisiensi elektrokoagulasi. Setiap perubahan tegangan akan menghasilkan efisiensi elektrokoagulasi yang berbeda.Tegangan yang digunakan semakin besar, maka nilai efisiensi dari elektrokoagulasi yang diperoleh semakin tinggi. Hal ini terjadi untuk setiap perubahan waktu kontak (waktu elektrokoagulasi), semakin lama waktu kontak menyebabkan nilai effisiensi elektrokoagulasinya semakin tinggi.

Reduksi aktivitas uranium tertinggi diperoleh pada tegangan 15 volt dan waktu proses selama 60 menit dengan penurunan uranium dalam limbah sebesar $97,738 \%$. Reduksimenandakan berkurangnya aktivitas uranium dalam limbah cair. Pada dasarnya pengukuran aktivitas bertujuan untuk mengetahui banyaknya oksigen yang diperlukan untuk mengoksidasi senyawa pencemar dalam air limbah. Hal ini sesuai double layer bahwa lingkaran terdalam akan diisi oleh koagulan bermuatan positif yangmenyerap ion-ion negatip pada lingkaran lebih besar. Muatan positip dan negatip bertemu maka terjadi gaya Van der Waals (tarik menarik) antar kedua ion tersebut sehingga terjadi ikatan yang sangat kuat dan terbentuknya flok yang dapat menurunkan aktivitas uranium dalam air limbah ${ }^{[15,16]}$.

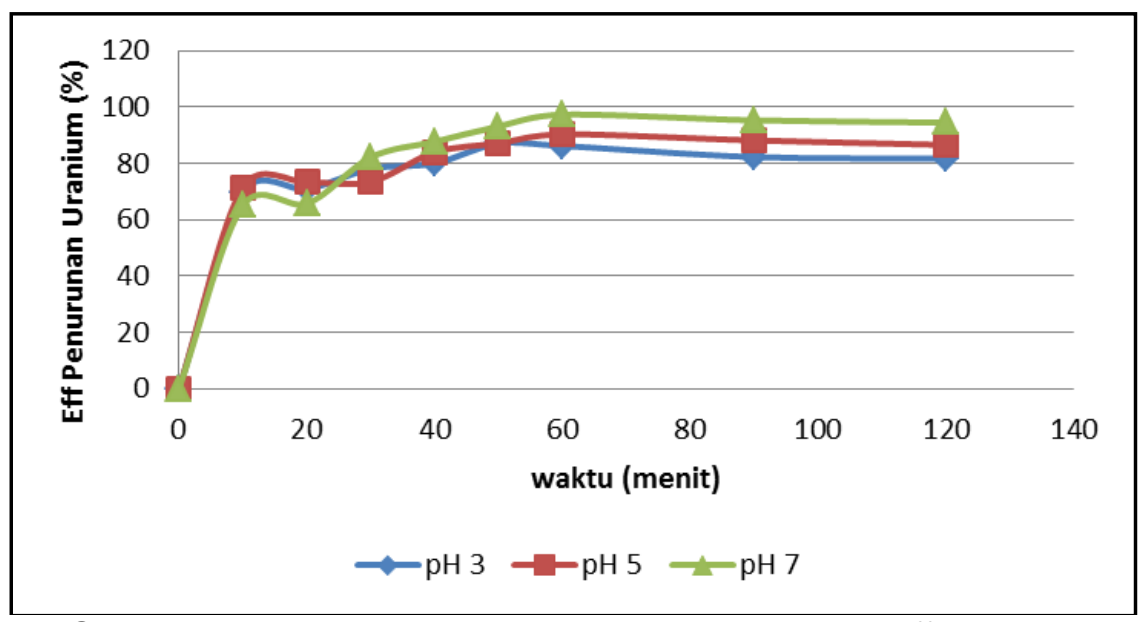

Gambar 8. Hubungan waktu proses dan $\mathrm{pH}$ terhadap effsiensi penurunan kadar uranium 
Gambar 8. Menunjukkan bahwa waktu proses elektrokoagulasi terjadi proses elektrolisis air yang menghasilkan gas hydrogen dan ion hidroksida semakin lama, maka gas hidrogendan ion hidroksida yang terbentuk semakin banyak, Apabila ion hidroksida yang dihasilkan semakin banyak maka akan menaikkan $\mathrm{pH}$ dalam larutan. yang mempengaruhi kondisi spesies pada larutan dan kelarutan dari produk yang dibentuk. Nilai pH larutan mempengaruhi efsiensi dan efektivitas elektrokoagulasi dan dengan mudah dirubah menjadi $\mathrm{pH}$ optimal yang terdapat dalam larutan berkisar $\mathrm{pH}$ antara 6,5 sampai 7,5.Gambar 8 dapat dilihat bahwa hubungan waktu proses dan $\mathrm{pH}$ terhadap efisiensi penurunan kadar uranium. Pada proses elektrokoagulasi terjadi oksidasi elektroda anoda dan terbentuk hidrogen pada katoda, Ion aluminium yang terlepas berinteraksi membentuk kompleks hidroksida yang dapat mempengaruhi nilai $\mathrm{pH}$ limbah cair. Ion hidroksil yang terlarut dalam limbah cair menyebabkan $\mathrm{pH}$ limbah menjadi meningkat seiring berjalannya waktu ${ }^{[6,17]}$.

Hasil analisis setelah melalui proses elektrokoagulasi dengan jumlah plat elektroda sebanyak 16 buah (katoda 8 buah dan anoda 8 buah) menunjukkan bahwa secara umum memberikan perubahan yang signifikan. Penurunan efisiensi aktivitas uranium dalam limbah sedangkan perubahan pH kurang signifikan bahwa pada proses elektrokoagulasi 60 menit mengalami peningkatan. Pada proses elektrokoagulasi terjadi pembentukan endapan dan flok-flok yang terapung (flotation), sebagai indikasi bahwa ion-ion $\mathrm{Al}^{2+}$ mengikat unsur uranium atau pengotor lainnya sangat efektif. Aktivitas uranium mengalami penurunan rata-rata mencapai $95 \%$ dari tertinggi pada proses elektrokoagulasi dengan waktu 60 menit dengan penurunan sebesar 97,285 \% pada $\mathrm{pH} 7$ dan 90, $271 \%$ pada $\mathrm{pH} 5$.

Besarnya $\mathrm{pH} 3$ tidak begitu mengalami perubahan yang berarti dan ada kecenderungan stagnan pada penggunaan 16 plat (katoda 8 buah dan anoda 8 buah). Hal ini dimungkinkan karena ion $\mathrm{Al}^{3+}$ dapat menimbulkan suasana basa dalam limbah jadi dapat diprediksi bahwa untuk limbah cair yang bersifat asam pengolahan dengan menggunakan elektrokoagulasi dapat menaikkan $\mathrm{pH}$ dengan efektif sampai rentang $\mathrm{pH}$ yang dibolehkan. Nilai $\mathrm{pH}$ hasil proses elektrokoagulasi masih memenuhi baku mutu limbah cair yaitu $\mathrm{pH}$ 6-9 sesuai Peraturan Menteri Lingkungan Hidup No. 5 tahun 2014. ${ }^{[18]}$

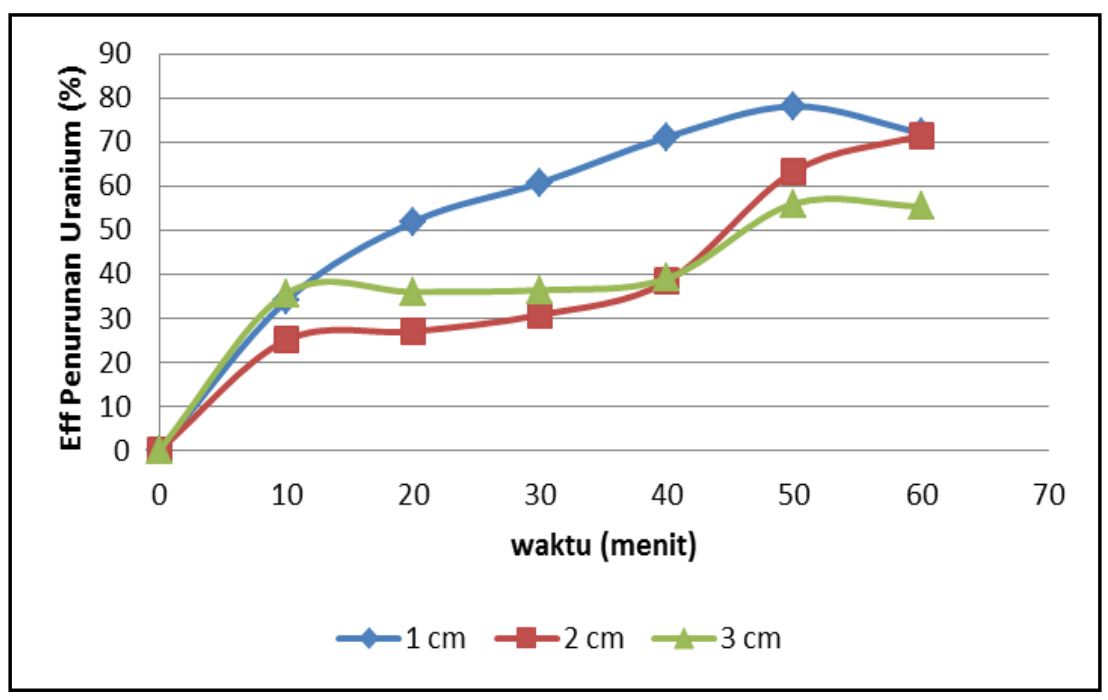

Gambar 9. Hubungan waktu proses, jarak elektroda terhadap effisiensi 
Gambar 9 menunjukkan probabilitas efek yang paling berpengaruh terhadap elektrokoagulasi adalah waktu, jarak antar elektrodadan saling berpengaruh lama waktu dan jarak antar elektroda karena mempunyai efisiensi penurunan yang besar. Dengan ketentuan perubahan hasil setelah mengalami proses elektrokoagulasi di dapat efisiensi perubahan aktivitas uranium sebesar $78,078 \%$ pada waktu proses 50 menit. Hal ini menunjukkan bahwa semakin lama dengan jarak elektroda yang semakin dekat maka penurunan aktivitas uranium juga akan semakin menurun. Jarak antara elektroda berpengaruh terhadap besarnya hambatan elektrolit. Jarak yang pendek antar elektroda dapat mengurangi hambatan ion dalam transportasinya ${ }^{[3,19] .}$ Semakin jauh jaraknya, maka hambatanya semakin besar, sehingga semakin kecil arus yang mengalir

\section{SIMPULAN}

Hasil penelitian pengolahan limbah cair yang mengandung uranium dengan metode elektrokoagulasi secara batch dengan variasi tegangan listrik dan waktu proses menunjukkan bahwa pada voltase 15 volt dan waktu proses selama 60 menit diperoleh hasil cukup baik. Semakin lama waktu proses elektrokoagulasi maka semakin tinggi tingkat efisiensi reduksi aktivitas uranium yaitu $97 \%$ pada $\mathrm{pH} 7$ dan jarak antar elektroda $1 \mathrm{~cm}$. Parameter proses elektrokoagulasi yang paling berpengaruh terhadap penurunan aktivitas uranium di dalam limbah cair adalah tegangan listrik dan waktu kontak. Elektrokoagulasi sebagai salah satu pengolahan limbah yang mengandung uranium dapat dilanjutkan dengan memvariasi parameter yang lain sehingga penelitian dan pengembangan ini lebih sempurna terutama pada pemakaian jenis elektroda dan jumLahnya, sehingga pemisahan senyawa-senyawa yang lain yang ada dalam limbah akan lebih tinggi.

\section{UCAPAN TERIMAKASIH}

Ucapan terima kasih kami sampaikan kepada penangung jawab DIPA PSTA Bapak Dr. Susilo Widodo tahun anggaran 2015-2016, yang telah memberikan dana untuk kegiatan litbang pengeIolaan limbah.

Bapak Triyono, ST yang telah membantu dalam rancangan dan pembuatan alat elektrokoagulator yang digunakan untuk litbang pengolahan limbah.

\section{DAFTAR PUSTAKA}

[1] Setiawan.,Sari,OV.,Bunawas,(2007)," Penentuan Konsentrasi Uranium dalam Air Minum dalam Kemasan (AMDK) Menggunakan Metode Jejak Fisi"Prosiding PPI-PDIPTN-BATAN, ISSN 0216-3128, Yogyakarta.

[2] Prayitno, Kismolo, E.,(2012), "Percobaan Awal Proses Elektrokoagulasi sebagai Metode Alternative Pengolahan Limbah Cair", PPI-PDIPTN, ISSN 0216-3128, Yogyakarta.

[3] Kamaraj, R.,Vasudevan,S., (2015), "Evaluation of Electrocoagulation Process for the Removal Strontium and Cesium from Aquaeous Solution", Chemical Engineering Reaserchand Design 93 page 522-530, India.

[4] Harif,T., Khai,M., Adin,A., (2012), "Electrocoagulation Versus Chemical Coagulation: Coagulation/flocculation Mechanisms and Resulting Flog Characteristics" Water Research 46,3177-3188, Elsevier.

[5] El Taweel,Y,et al, (2015), "Removal of $\operatorname{Cr}(\mathrm{VI})$ lons from Waste Water by Elektrocoagulation Using Iron Electrode", Egyptian journal of petroleum 24, , pp 183-192.

[6] Guzman,A.,et al, (2015), "Arsenic and Fluoride Removal from Ground Water 
by Electrocoagulation Using a Continous Filter Press Reactor', Chemosphere 144 page 2113-2120, Mexico.

[7] Kobya,M.,Demirbas,E.,(2015),"Evalua tion of Operating Parameters on Treatment of can Manufacturing Wastewater by Electrocoagulation", Journal of Water Process Engineering 8.64-74, Elsevier, Turkey.

[8] Mutiara AS., Chellam, S., (2015), "Mechanisms of Boron Removal from Hydraulic Fracturing Wastewater by Alumunium Electrocoagulation" Journal of Colloid and Interface Science 458, 103-111, Elsevier.

[9] Noname. (11 May 2016). Ilustrasi Proses Elektrokoagulasi Available: http:// (www.cr-enviro.com).

[10] Demirci,Y.,Pekel,L.,Alpbaz,M.,(2015)," Investigation of Different Electrode Connections inElectrocoagulation of Textile Wastewater Treatment', International Journal of Electro-chemical Science 10, page 2685-2693, Turkey.

[11] Basuki,Tk.,Wisnu,M.A.,Sudibyo,(200), "Pengaruh $\mathrm{pH}$ dan Tegangan pada Pembuatan Serbuk Itrium Hasil Proses Pasir Senotim dengan Elektrolisis",Seminar Nasional V SDM Teknologi Nuklir Yogyakarta, ISSN 1978-0176

[12] Mukminim,A.,(2006), "Pengolahan Limbah Industri Berbasis Logam Dengan Teknik Elektrokoagulasi Flotasi, Program Magister IImu Lingkungan, Universitas Diponegoro, Semarang.

[13] Holt,P., Barton,G., Mitchel,C., (2005), "The Future for Electroco-agulation as a Localised Water Treatment Technology, Chemos-phere 59 page 355-367, Australia.

[14] Eka Wardhani, Mila Dirgawati, Karina Putri Valyana,(2012), "Penerapan Metode Elektrokagulasi Dalam Pengolahan Air Limbah Industri Penyamakan Kulit", Seminar Nasional, Penelitian Masalah Lingkungan di Indonesia 8, Kampus UGM, 12 Juli 2012.

[15] Dehghani,M., et al, (2014), "Application of Electrocoagulation Process for Reactive red 198 Dye Removal from The Aqueous Solution", Iranium Journal Of Health Sciences 2 page 19, Iran.

[16] Gatsious,E., et al, (2015),"Optimization of Elektroco-agulation Process for the Purification of a Real Industrial Wastewater from Toxic Metals" Journal of Environmental Management 154 page 117-127, Greece.

[17] Farida Hanum, Rondang Tambunm, Yusufritonga, William Wardana Kasim,(2015), "Aplikasi Elektro Koagulasi Dalam Pengolahan Limbah Cair Pabrik Kelapa Sawit", Jurnal Teknik Kimia USU, Vol 4 No. 4 , Desember 2015.

[18] Peraturan Menteri Lingkungan Hidup Republik Indonesia No 5 Tahun 2014, Tentang Baku Mutu Air Limbah.

[19] Ezechi E.H, Isa M.H, Kutty S.R, Yaqub A., 2014, "Boron Removal From Produced Water Using Electrocoagulation", Process Safety and Environmental Protection 92, page 509-514, Malaysia. 